\title{
A Curriculum in Urban Agriculture and Sustainability and Lessons Learned
}

\section{Dr. Lisa Deane Morano, University of Houston - Downtown}

Lisa Morano is a Professor of Biology and Microbiology at the University of Houston-Downtown (UHD). She is also the Director of the Center for Urban Agriculture and Sustainability (CUAS) at UHD. Her research has focused on the bacteria found inside plants including plant pathogens and non-pathogenic inhabitants called endophytes. Her research has also included multiple USDA-NIFA funded programs that have led to the creation of new curriculum and experiential learning opportunities through the CUAS. She teaches multiple courses in environmental biology and sustainability and she organizes an experiential learning program where students work in teams to build solar-powered technology that addresses a need in urban agriculture.

\section{Dr. Vassilios Tzouanas, University of Houston, Downtown}

Vassilios Tzouanas is an Associate Professor and Chairman of the Computer Science and Engineering Technology department at the University of Houston - Downtown, in Houston, Texas. He received all his degrees in chemical engineering and obtained his Ph.D. from Lehigh University. He has worked in the industry for 19 years where he held technical and management positions with major operating companies as well as process control technology development companies. Since 2010, he has been with UHD. Dr. Tzouanas' research interests include process modeling, simulation and design, process control, and renewable energy systems. Dr. Tzouanas is an ABET Program Evaluator (PEV) for Engineering and Engineering Technology programs. He is also member of AIChE and ASEE, and currently serves as ETD Director. 


\title{
A Curriculum in Urban Agriculture and Sustainability and Lessons Learned
}

\begin{abstract}
Large cities, like Houston, are growing fast and they face numerous environmental and food distribution problems. These problems require collaborative and multi-disciplinary approaches to solve. Furthermore, many city residents are interested in more locally grown food, better water quality and more sustainable city practices. However, most residents do not have access to the information which would allow them to help solve complex issues needed to engage in sustainable practices and urban agriculture. This paper describes the curriculum and an experiential learning program developed within the Center for Urban Agriculture and Sustainability (CUAS) at the University of Houston-Downtown (UHD). All UHD undergraduates have access to four new courses that can be taken as individual electives or collectively (with three additional UHD courses) for a minor in Sustainability. Unlike many universities where sustainability is only in environmental engineering or biology, this minor is open to every students. Undergraduates interested in sustainability can also apply for Experiential Learning in CUAS (EL CUAS). Through EL CUAS, 8 to 10 undergraduates per year work collaboratively in a yearlong program where they complete courses, participate in professional development and carry out a project with a sustainability or urban agricultural focus. Students selected for the experiential learning (both science and non-science majors) gain valuable project management skills, communication skills and the ability to scientifically analyze project data. All groups are also required to design and build technology to solve a sustainability or urban agriculture problem. Thus, this program is moving the principles of engineering technology beyond just ET majors. The benefits of this program are more educated citizens with the skills to tackle the complex food and environmental issues facing cities. Our goal is for this curriculum to eventually be expanded so that it may be offered to members of the Houston community as a certificate in Sustainability. This paper presents the new curriculum and Minor in Sustainability, discusses collaborative experiential learning projects developed by undergraduate students and summarizes learning experiences and skills developed by students that participated in EL CUAS.
\end{abstract}

\section{Introduction - Need for Sustainability Curriculum and Initiatives}

The world faces unprecedented challenges in the year 2020. These challenges include, but are not limited to: climate change ${ }^{[1]}$, biodiversity loss, resource use for a growing population, expanding need for agricultural land, limited fresh water and chemical pollution including disruption of the nitrogen cycle ${ }^{[2]}$. Despite these challenges, there are reasons for optimism. First, more people are living in urban centers than rural areas. Cities are an energetically efficient approach to offering services to large populations of people and if they are well designed for walkability they can reduce the average carbon footprint per person ${ }^{[3]}$. Second, the world is becoming aware that a sustainable approach to the future is a necessity. The sustainability triangle includes the three sides of environment, social stability and economics. It is becoming increasingly obvious to agencies, companies and governments that we must develop future plans that consider the interaction of these three aspects of sustainability and this approach must be incorporated into higher education ${ }^{[4]}$. Finally, the current generation of young adults are the most environmentally and socially conscious in history. These students understand the complexities the world is facing and know they will need to be part of the solution. 
Houston is the fourth largest city in the US and it is the ethnically most diverse large city in America ${ }^{[5]}$. Like all large US cities it struggles with dramatic income disparity between neighborhoods. Childhood obesity is on the rise and Houston has a number of food deserts, defined by the USDA as neighborhoods where there is limited access to fresh, affordable food ${ }^{[6]}$. The question of how to improve the access and distribution of food throughout Houston and how to create healthy, sustainable neighborhoods is a central focus on many Houston groups including a few non-profits, county agencies and new local urban farms. In addition, the University of UHD created the Center for Urban Agriculture and Sustainability (CUAS) with the mission to support healthy Houston neighborhoods through research, service and teaching.

It is critical that all university students have the opportunity to study sustainability. Sustainability as a cross-disciplinary field has been around for decades. However, during the last number of years has there been a shift in the global mindset that sustainability thinking is not just a fringe idea, but that it plays an important role in creating long-term economic health, the social stability of systems and protecting the ecosystem services on which the world depends. According to the Association for the Advancement of Sustainability in Higher Education (AASHE), every college graduate today, regardless of major, will be impacted by some aspect of sustainability in their future career ${ }^{[7]}$. Students of any major with some knowledge of sustainability principles will have an advantage in the job market.

The job of universities is to educate and inspire students. The focus of the CUAS has been not to try to fix Houston neighborhoods directly, but to train UHD students so that they may graduate and work to address the problems of their neighborhood or region or even globally. In order for us to make students successful they need both knowledge and practice. The goal of this paper is to outline the curriculum we have developed as part of a Minor in Sustainability. The minor combines courses in sustainability basics, renewable energy technology, a seminar to review the academic literature and hands-on capstone courses. We also have developed a cross-disciplinary experiential learning program where students work together to solve a real-world problem in Houston. Student teams must create a system that improves urban agriculture using only renewable energy. We highlight the value of combining teams of diverse majors and engaging them in a project with design and engineering components. Students in these crossdisciplinary teams learn how to work together, how to combine engineering and science principles in problem solving and they gain the confidence and leadership opportunities they will need to solve problems when they leave UHD.

\section{Curriculum}

Several years ago the CUAS developed curriculum in support of a new Minor in Sustainability. Often a minor in sustainability is limited to specific programs or specific students such as those in an environmental engineering, biology or urban planning. Because the courses require numerous prerequisites within the majors, these minors are for all practical purposes out of reach to other majors. We designed a Minor is Sustainability with a new SUST prefix that is open to all UHD undergraduates. We are proud of this innovative, cross-disciplinary curriculum as solving future issues with social and economic components will require majors outside of the environmental sciences.

The Minor in Sustainability is 18 hours (6 courses). Three of these courses can be selected as part of the degree plan of most students if they choose wisely from the list of course options. For these three courses students must take one course from each of three course areas. The areas include 1) environmental science fundamentals, 2) social and ethical considerations and 3) technical and business applications. An 
important addition to the technical and business application category has been the development of Renewable Energy Systems (SUST 3301). In addition to the three courses above, the student must then complete three SUST courses including Fundamentals of Sustainability (SUST 3302), Seminar in Sustainability (SUST 4301) and Capstone in Sustainability (SUST 4302). These courses are currently taught by one faculty member in the department of Natural Sciences (NS) and one in Computer Science and Engineering Technology (CSET).

\section{Experiential Learning}

Students must gain both knowledge and confidence to create solutions to the problems they see around them. They need to learn to work in cross-disciplinary teams working toward a common goal or a deadline. The best way to accomplish these goals is to engage students in experiential learning. The CUAS has hosted multiple years of a high-impact Experiential Learning through CUAS (EL CUAS). This program was funded by a USDA NIFA educational grant aimed at increasing the number of underrepresented students pursuing careers in food, agricultural, natural resources or related humanfocused careers. UHD is an excellent institution for such a program as it is both a Minority-Serving Institution (MSI) and a Hispanic Serving Institution (HSI) with an underrepresented minority population that make up over $70 \%$ of the student population. For each of the last 4 years, the two faculty members in NS and CSET have mentored 8-10 students in EL CUAS.

There are numerous elements of the EL CUAS program that have made it impactful. The students in the program work in teams to complete relevant projects. Projects have multiple components including science, design and engineering. A review of some sample student projects are outlined in the section below. Depending on the majors in the group they must also include social science, business or education components. Students in the EL CUAS received mentoring by the two faculty who created the program and by additional faculty or staff with particular expertise (Career Center, Center for Critical Race Studies, Metacognition and Learning and Center for Public Deliberation). The EL CUAS students also went on field trips to relevant facilities including: USDA ARS Children's Nutrition Center lab at Baylor College of Medicine, Urban Harvester Aquaponics facility, local urban farms and community gardens.

\section{Sample Projects}

This section presents a number of projects completed by EL CUAS students. Each of these projects has a focus on sustainability and/or urban agriculture. Teams of students worked collaboratively to design, implement and automate the operation of their project. Mostly, teams were comprised of biology and engineering technology students even though students from social sciences and interdisciplinary studies were present in small numbers and had a significant impact.

\section{a. University Sustainability Garden}

The objective of this project has been to develop a garden at the UHD where biology students could grow different types of produce, perform various experiments on how to maximize production, and finally share the produce with University's food bank to support students in need of fresh produce. To meet the energy needs of the garden and automate the irrigation system, students were responsible for the selection and implementation of renewable energy systems (photovoltaic panels and wind turbine) and the development of the automation strategies. As shown in Figure 1 (below), a combination of photovoltaic 
panels and wind turbine are used to generate the needed energy. A bank of batteries is used to store energy. Soil moisture sensors are used to activate the irrigation system for each of the beds independently.

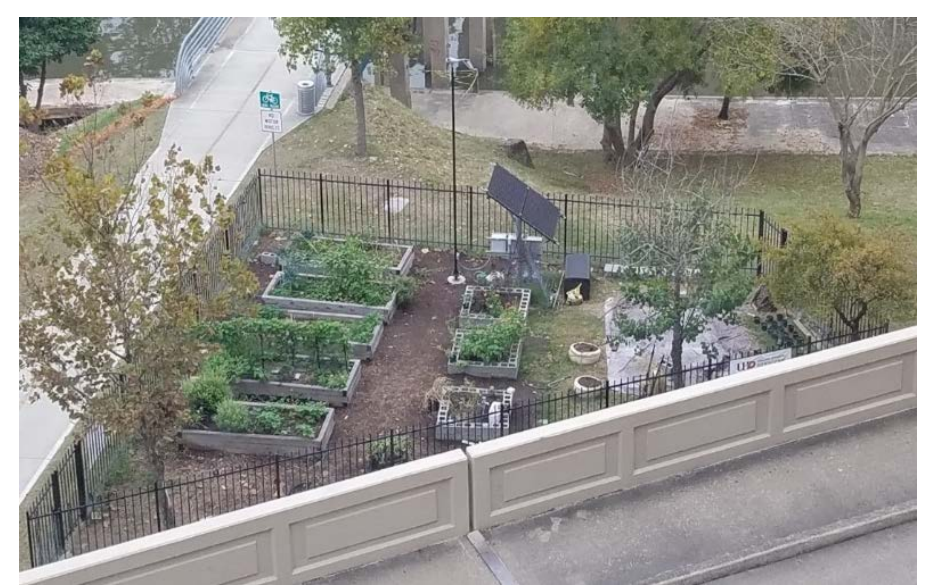

\section{b. Aquaponics System}

Figure 1. The as-built UHD Sustainable Garden

The objective of this interdisciplinary project was to address a problem related to sustainability which was the design of an aquaponics system using renewable energy sources. Such a project helped students practice and further improve skills related to teamwork, communication, and work planning/management when working with others who do not necessarily "speak" the same technical/scientific language. Engineering technology and biology students worked together to design and build the fully instrumented and automated aquaponics system at our university’s sustainability garden. From a team leading viewpoint, biology students defined the requirements for the aquaponics system while engineering students led the activities to design and build the system. The developed system allows interested students to study the growth and optimize the production of vegetables. In addition, this student-driven project revitalized and optimized the sustainability garden of the university from a controls and instrumentation viewpoint. This garden was destroyed during hurricane Harvey, two years ago and this project was a pivotal piece in rebuilding its functionality. Figure 2 shows the as built system.

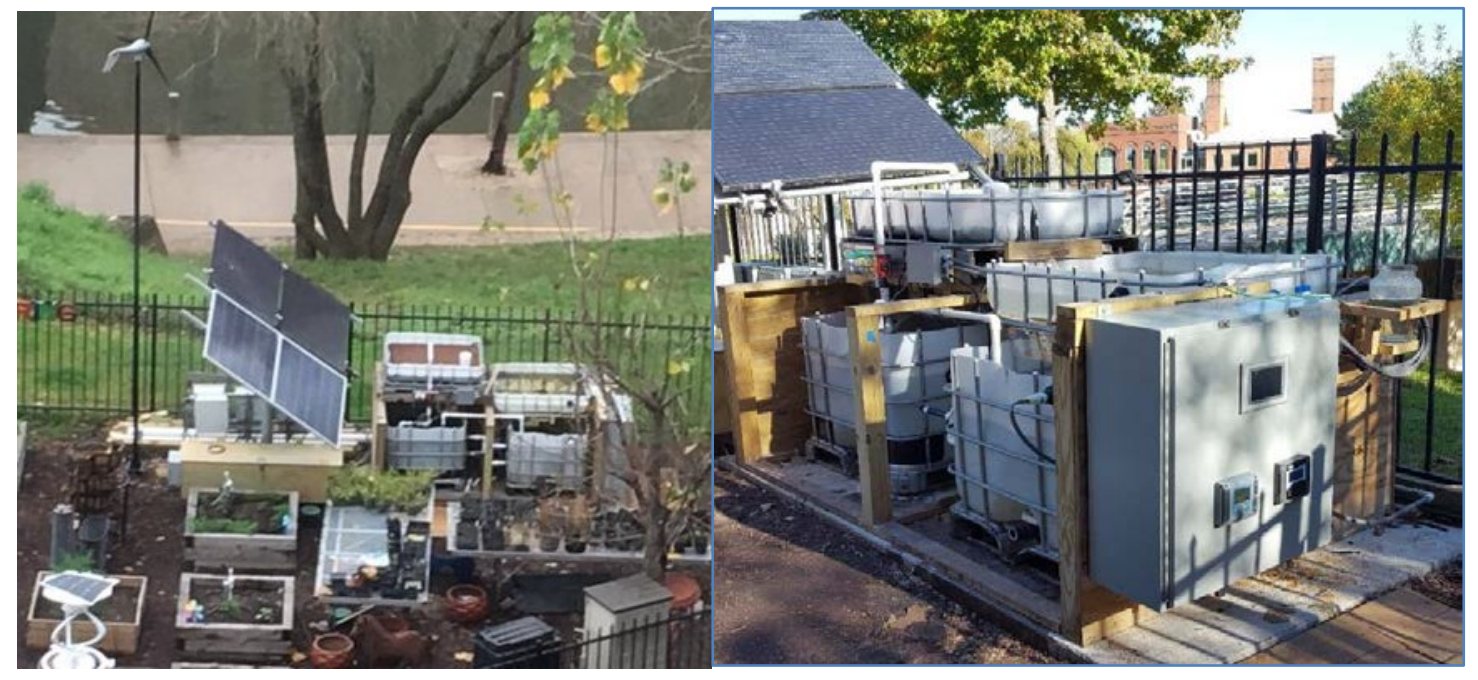

Figure 2: Aquaponics System 


\section{c. Community Garden}

The objective of this project was to bring energy to a community garden, develop an irrigation system, grow various vegetables, and work with the management of the garden and local community leaders to best distribute the produce. Biology, engineering technology, and social sciences students worked on this community garden project. The as built system is shown in Figure 3.

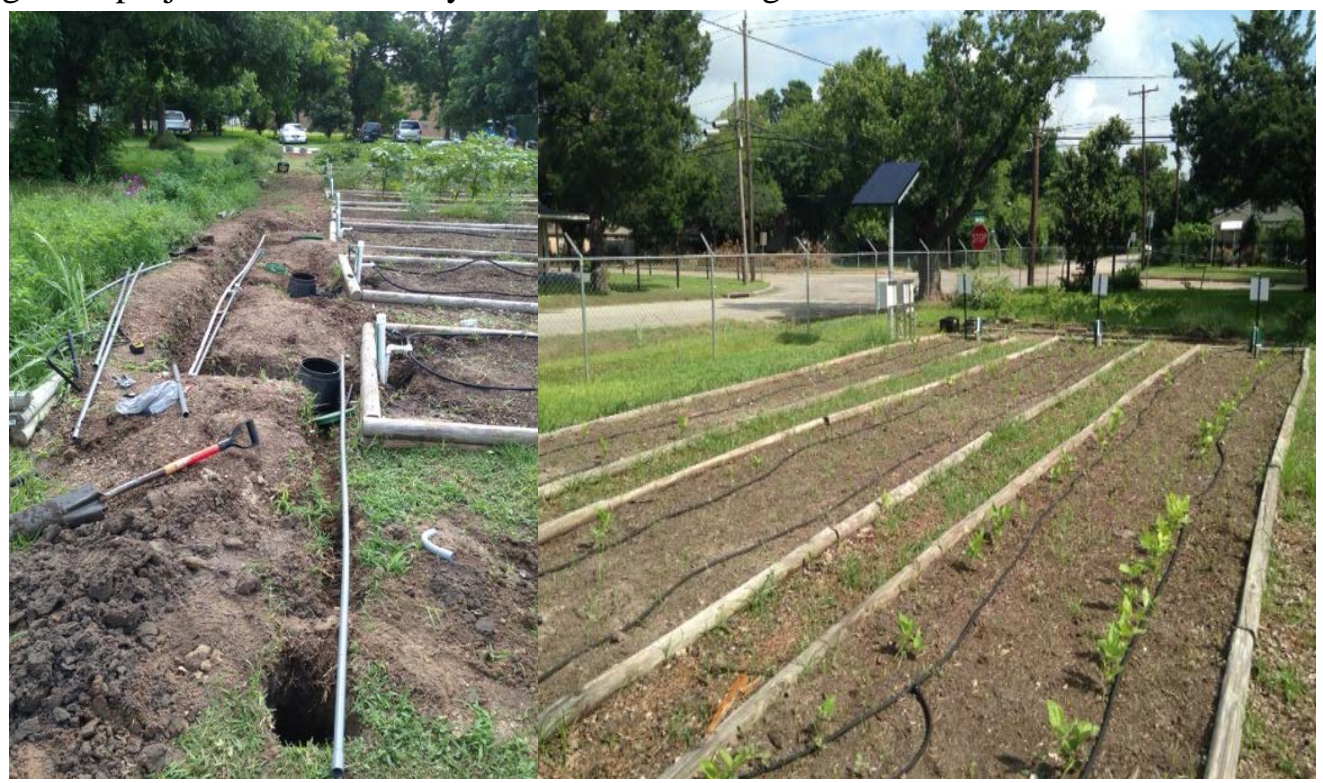

Figure 3: Installation of Community Garden Irrigation System and Solar Panels

\section{d. Bioethanol Production}

The objective of this project has been to study the production of bioethanol from organic waste rich in glucose as an alternatively to the production of bioethanol from corn. The project included the design, implementation, automation of the bioreactors along with studies on the fermentation yield from various feedsctocks which included food waste such as apple peels and banana peels. Again, biology and engineering technology students have worked on this projects and developed three bioreactors. Figure 4 shows the first of the bioreactors developed.

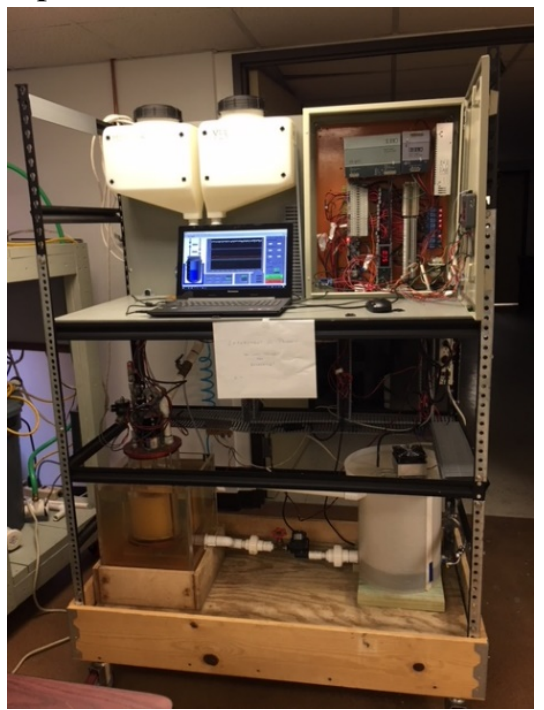

Figure 4: Bioreactor for Bioethanol Production 


\section{e. Automated Composter}

The objective of this project has been to develop a composter and automate its operation using energy harnessed using renewable energy sources. Its simple design and automated operation make this composter ideal for household use, thus reducing the amount of waste which is sent to landfills. Figure 5 shows the as-built automated composter which is powered using solar energy. The composter is automated to turn-on for several revolutions every afternoon. This automation also will improve the speed of household compost made as many homeowners forget to "turn" their compost bin.

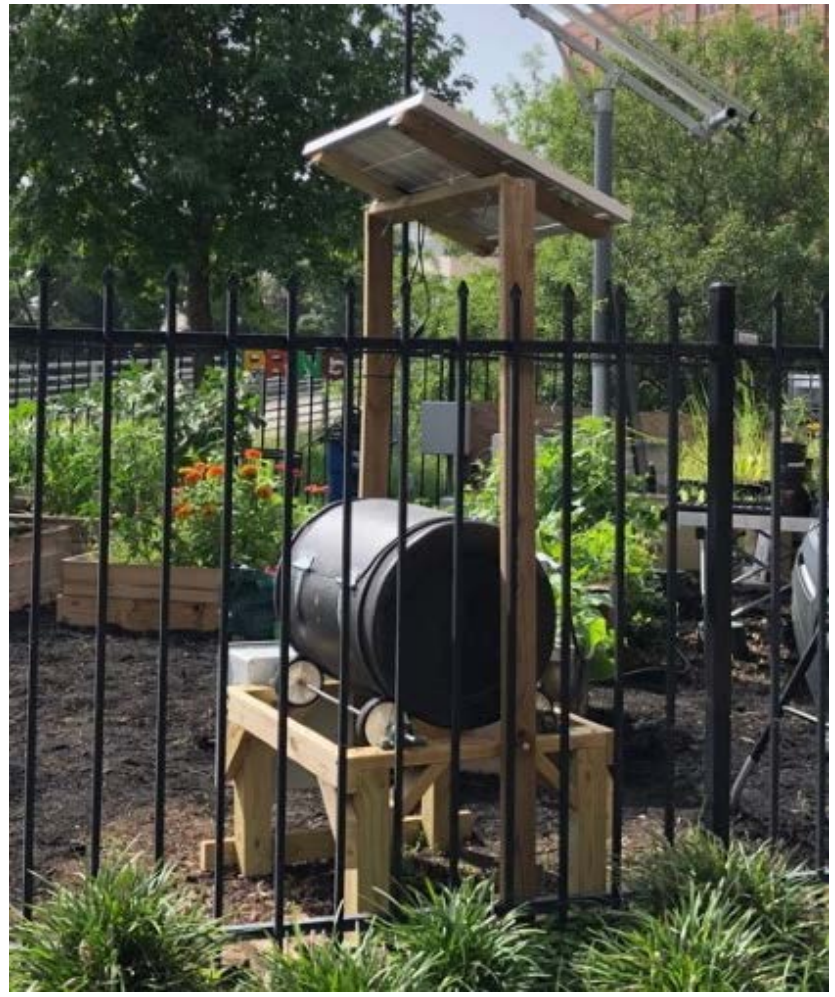

Figure 5. The Automated Composter

\section{Program Assessment and Lessons Learned}

As mentioned earlier, through the EL CUAS program, 8 to 10 students each year over a period of four years participated in experiential learning activities by working in teams. As EL CUAS was part of a USDA NIFA funded grant program, a detailed evaluation of the program including qualitative and quantitative student data was carried out. The evaluation was conducted by the external evaluator Integrated Learning Innovations, Inc. Students were given pre and post surveys to evaluate their familiarity with concepts in sustainability and the level of confidence about graduate school, working as a team, giving an oral presentation and other important professional soft skills. Students were also asked to respond to open questions about the program. Key highlights from the annual assessments and comments by the external program evaluator are summarized in the following paragraphs. For simplicity we have focused on the data from the last cohort of the program, but it is representative of previous years.

\section{a. Diversity}

UHD is a Minority Serving Institution and a Hispanic Serving Institution which serves a large segment of the city's underrepresented population. As the program at this university would automatically have a 
racially diverse group of students we focused on making sure there was also a diversity of students based on additional parameters of socioeconomics and educational environment the students came from. For Cohort 4, the external program evaluator found out that one quarter of the cohort were low-income families and Pell-grant eligible, over 12 percent came from environments with limited opportunities for higher education and over $60 \%$ were both first-generation college students. This is down slightly from previous years when students were first generation college students at percentages of between 70 and almost 90\% (ILI, Inc.)

\section{b. Knowledge gain}

Pre and post-surveys were used to assess gains in students' knowledge about issues/terms in sustainability and urban agriculture. In the period between the start of the program, in January, and the conclusion of the summer activities (in late July), there was significant gain in students' knowledge about issues/terms related to sustainability. According to the external program evaluator, there was significant gain regarding student's ability to define important sustainability terms or phrases. The phrase "sustainability resources" increased from $75 \%$ to $100 \%$. The phrase 'buying local” increase $62.5 \%$ to $100 \%$. The phrase 'ethical labor practices had an increase from 62.5 to $100 \%$. Understanding of the term 'organically grown' increased from $75 \%$ to $100 \%$ and 'food desert' from 12.5 to $87.5 \%$. The phrase 'renewable energy' had no change, but remained at a $100 \%$ understanding and finally, 'urban agriculture' showed an increase from 75 to $100 \%$ (ILI, Inc.).

Compared to Cohort 4, prior cohorts had larger gains in knowledge with respect to the above gains. For instance, regarding Ethical labor practices, 27\% in Year 1, 20\% in Year 2, and 33\% in Year, of the students were not sure about this term at the start of the program in January. One optimistic view of this observation is that knowledge about sustainability is increasing across all students attending the university over time.

\section{c. Skills development}

One of the goals of EL CUAS program is to provide opportunities for skills development through experiential learning, professional development activities, and high impact practices by participating in research. In order for the external evaluator to determine if the students were gaining skills development opportunities students were asked to comment on how many high-impact activities they felt they were engaged in between the start and the end of the program. Data collected on this topic are summarized below.

a) For experiential learning, the percentage of students reporting either 1 or 2 opportunities or more than 2 opportunities increased from $62.5 \%$ to $100 \%$ over the program period.

b) For professional development, the percentage of students reporting either 1 or 2 opportunities or more than 2 opportunities increased from $87.5 \%$ to $100 \%$ over the program period.

c) For doing a scientific research project, the percentage of students reporting either 1 or 2 opportunities or more than 2 opportunities increased from $87.5 \%$ to $100 \%$ over the program period.” 
What can be summarized from above is that not only did the faculty design features of experiential learning, professional development and research into the project, but that students perceived that they gained these high-impact activities, as well.

\section{d. Teamwork}

The importance of teamwork is emphasized to EL CUAS participants and practiced throughout the duration of the program by all involved including students, staff, and faculty. It is the expectation of all EL CUA participants to work together to solve problems related to sustainability and simultaneously develop skills required for a successful professional career. We also frequently acknowledged that teamwork and working together with people from diverse backgrounds is challenging, but that it is in this challenge that the greatest knowledge gain and problem-solving capabilities are found.

Open-ended evaluation questions were posed to students at the end of program. In response to the first question: "If you had to pick one thing that you have learned by participating in this program, that you think will stick with you for a long time, what would that be?” about $50 \%$ or the responses focused on teamwork:

a) "Diversify the backgrounds of people working together to solve sustainable issues, this will ensure the best solution"

b) "Something that I will carry on will be the appreciation and value that I have grown for working in a diverse group. Working with others yields faster problem-solving and more creative and effective solutions"

c) "The importance and benefits of working in a multidisciplinary team to accomplish a project"

d) "Integrative education is the best way to learn something and apply that knowledge. This incorporates a variety of perspectives and knowledge bases to accurately address an issue"

When students were asked about any additional comments they would make, there were also comments related to teamwork including:

a) "Amazing opportunity for undergraduates, provides essential learning scenarios and networking resources. Connects individuals from multiple disciplines in a unique and professional manner."

b) "Lastly, I was able to learn from my peers not only technical information, but I was able to see how they approached problems and thus learned new ways of thinking."

c) "This program has completely shaped the way I view sustainability and allowed me to understand the perspectives of students in other disciplines to better promote sustainable practices."

\section{f. Student satisfaction}

The students' comments about the EL CUAS program in general also provided the opportunity to look at general student satisfaction, which was notably positive. A selection of particularly thoughtful students comments that speak to the value of the EL CUAS program are provided verbatim below:

a) "Getting out of your comfort zone is where the magic happens" 
b) “This program was amazing. I was able to practice my public speaking skills, which has always been a huge barrier for me. I was able to apply what I have learned in my engineering courses to solve problems and thus reinforce the technical knowledge learned in class. Lastly, I was able to learn from my peers not only technical information, but I was able to see how they approached problems and thus learned new ways of thinking."

"This project is amazing. It allowed me to get outside of my comfort zone and revealed potential I didn't know I had. This was the best experience I could have had and I'm very grateful for the opportunity to be chose to experience it."

\section{Discussion}

Incorporating sustainability into the higher education curriculum is challenging, but doable. In 2002, David Orr, a leader in sustainability, wrote a seminal piece about the four challenges of sustainability. ${ }^{[9]}$ One of those four challenges was engaging in improved sustainability education. ${ }^{[9]}$ Over the last few years there have been publications highlighting the need for sustainability in the curriculum within a number of fields. There has long been an interest in incorporating sustainability to environmental biology and environmental engineering. However, there are examples and calls for sustainability to move into civil engineering curriculum ${ }^{[10]}$, curriculum for property, construction and project management ${ }^{[11]}$, mainstream business curriculum ${ }^{[12]}$ and even nursing curriculum ${ }^{[13]}$. In addition to papers about curriculum in a particular field, there are numerous publications outlining the challenges of designing inclusive sustainability curriculum ${ }^{[14]}{ }^{[15]}$. Challenges include territoriality of information, the structure of universities with strict divisions (committees, spending accounts, etc.) and finally, the general lack of time and financial resources which limit what any individual or small group of faculty can usually do. ${ }^{[15]}$ These challenges were definitely apparent when setting up this collaboration. Those who have outlined how change can happen have focused on taking a holistic system approach, to create a vision for the program and to try to foster supportive leadership. ${ }^{[14]}$ We have tried to keep this program focused on crossdisciplinary teams and hands-on student-learning as the central themes to share the passion of sustainability. We have also had the luck of a supportive Dean for the College of Science and Technology under which both the Departments of Natural Sciences and Computer Science and Engineering Technology are both located.

There appears to be a trend in sustainability education toward any activities that support student projects and partnerships. Faculty from universities in California have argued that an interdisciplinary sustainability approach that focuses on local problems is best. It will teach local problem solving, time management and create community. ${ }^{[15]}$ They argue that such team-focused projects reward collaboration and team accomplishment not individual learning and competition. ${ }^{[15]}$ Not only will such skills be useful for solving future sustainability problems, but they are skills most employers are looking for. Such innovation is not unusual for well-funded California universities, but we are excited to be trying similar innovations at an urban university in Texas. There is also literature in sustainability curriculum to suggest that community partnerships can be an enormous asset. ${ }^{[16]}$ We are in agreement that these partnerships can be invaluable. We have engaged in one group project at a community garden (mentioned above). As field trips we have visited local sustainable energy companies, urban farms science labs and non-profits for field trips. As students have started enrolling in the Minor in Sustainability most of them have engaged with our sustainability for their capstone projects. This has strengthened collaboration with the 
Center and led to additional research opportunities. Therefore, our curriculum and experiential learning programs have also created greater connection within the sustainability community.

\section{Conclusions}

The CUAS has successfully created the new curriculum and a successful experiential learning program. The Minor in Sustainability has graduated seven students from a variety of degrees and all students have had innovative capstone projects including the creation of a campus bio swale, successful USDA application for a local farm to take SNAP dollars and an economic evaluation of the new LEED Gold certified science building on campus. The collaboration between different Departments has led to valuable faculty collaboration on additional funding to support the CUAS. The Experiential Learning in the CUAS (EL CUAS) has been both effective and rewarding both in terms of student impacts and project sophistication. The EL CUAS students have all learned basic engineering technology principles and this is particularly impactful for the students outside of Engineering Technology. Science, Social Science and Business majors also teach the Engineering Technology students important principles about the scientific methods, human motivation or economic impacts. These projects also give students a great sense of accomplishment and autonomy. Despite the fact that cross-disciplinary projects are difficult to establish their pay off can be enormous for the students and the faculty. Experiential learning as outlined in this paper is also the best way to prepare the future generation of students to address our current environmental issues with sustainable technologically-inspired solutions.

\section{Acknowledgements}

This program was established and carried out as outlined in a grant funded by the USDA NIFA grant 2015-38422-24081. We would like to thank the external evaluator Integrated Learning Innovations, Inc. for their collection and analysis of student evaluation data in compliance with the UHD Human Subjects guidelines.

\section{References}

[1] US Global Change Research Program. 2018. Fourth National Climate Assessment: Volume II Impacts, Risk and Adaptation in the United States Overview. 41 pgs.

[2] Sachs, J. 2015. The Age of Sustainable Development. Columbia University Press, New York, NY. 543 pgs.

[3] Fan, P., Wan, G., Xu, L., Park, H., Xie, Y., Liu, Yue, W. and J. Chen. 2018. Walkability in urban landscapes: a comparative study of four large cities in China. Landscape Ecol 33:323-340.

[4] Cebrian, G. 2018. The I3E model for embedding education for sustainability within higher education institutions. Environmental Education Research. 24(2):153-171.

[5] Capps, R., Fix, M. and C. Nwosu. 2015. A Profile of immigrants in Houston, the nation's most diverse metropolitan area. National Center on Immigrant Integration Policy.22 pgs. www.migrationpolicy.org

[6] United States Department of Agriculture Economic Research Service. Definitions. Retrieved January 30, 2020 from www.ers.usda.gov.

[7] Fang, C. (January 9, 2013). Ten ways to integrate sustainability into the curriculum. The Association for the Advancement of Sustainability in Higher Education. Retrieved from asshe.org.

[8] https://www.faeis.cals.vt.edu/index.php/data-center/

[9] Orr, D. 2002. Four challenges of sustainability. Conservation Biology. 16(6); 1457-1460.

[10] Chau, K. 2007 .Incorporation of sustainability concepts into a civil engineering curriculum. J. Prof. Issues. Eng. Pract. 133(3):188-191. 
[11] Stubbs, W. and J. Schapper. 2011. Two approaches to curriculum development for educating for sustainability and CSR. International Journal of Sustainability in Higher Education. 12(3):259-268.

[12] Hayes, C. and S. Holdsworth. 2008. Curriculum change for sustainability. Journal for Education in the Built Environment. 3(1):25-48.

[13] Goodman, B. 2011. The need for a 'sustainability curriculum' in nurse education. Nurse Education Today. 31(8):733-737.

[14] Wright, M. and F. Monsour. 2015. Beyond sustainability: A context for transformative curriculum development. Transformative Dialogues: Teaching \& Learning Journal. 8(2): 19 pgs.

[15] Bacon, C., Mulvaney, D., Ball, T., DuPuis, M., Gliessman, S., Lipschutz, R. and A. Shakouri. 2010. The creation of an integrated sustainability curriculum and student praxis projects. International Journal of Sustainability in Higher Education. 12(2):193-208.

[16] Allen-Gil, S., Walker, L., Thomas, G., Shevory, T. and S. Elan. 2005. Forming a community partnership to enchance education in sustainability. International Journal of Sustainability in Higher Education. 6(4):392-402. 